\title{
Bir Havalimanı Otoparkına Kurulabilecek Fotovoltaik Üretim Sisteminin Tasarımı ve Enerji Analizi
}

\author{
S1tk1 Güner ${ }^{*}$, Abdurrahman Muharremoğlu ${ }^{2}$ \\ ${ }^{1}$ İstanbul Arel Üniversitesi, Mühendislik-Mimarlık Fakültesi, Elektrik-Elektronik Mühendisliği Bölümü, İstanbul, Türkiye (ORCID: 0000-0003-1085-0474) \\ 2 İstanbul Arel Üniversitesi, Mühendislik-Mimarlık Fakültesi, Elektrik-Elektronik Mühendisliği Bölümü, İstanbul, Türkiye (ORCID: 0000-0002-9195-287X)
}

(İlk Geliş Tarihi 2 Nisan 2020 ve Kabul Tarihi 23 Mayıs 2020)

(DOI: 10.31590/ejosat.713529)

\begin{abstract}
ATIF/REFERENCE: Güner, S. \& Muharremoğlu, A. (2020). Bir Havalimanı Otoparkına Kurulabilecek Fotovoltaik Üretim Sisteminin
\end{abstract} Tasarımı ve Enerji Analizi. Avrupa Bilim ve Teknoloji Dergisi, (19), 182-188.

\section{$\ddot{O} \mathbf{z}$}

Dünyada karbon emisyonu azalıımı ile ilgili farkındalık artıkça yenilenebilir enerjiden elektrik üretimi yatırımları buna paralellik göstermektedir. Özellikle ülkemizde son yıllarda güneş enerjisi santralleri (GES) elektrik güç sisteminin gözde konularından biridir. Fakat büyükşehirlerdeki arazi fiyatlarının yüksek olması bu santrallerin önündeki en büyük engeldir. Havalimanları gibi kamu alanlarının otoparklarına yapılacak fotovoltaik üretim sistemleri (FVÜS) hem bu alanların ikincil kullanımına imkân verirken, hem de FVÜS'nin yatırım maliyetini düşürerek yatırıma daha uygun hale gelmesini sağlar. Ayrıca otoparka kurulacak FVÜS ile araçlar için gölgelenme alanı oluşturularak güneşin araçlar üzerindeki etkisi azaltılabilir. Bu çalışmada Adnan Menderes Havalimanının otoparkına kurulabilecek bir FVÜS'nin tasarımı ve ürettiği enerji ile otoparkın enerji ihtiyacını karşılayıp karşılamadığının analizinin yapılması amaçlanmıştır. Bunun için otoparka kurulabilecek FVÜS bir benzetim programı kullanılarak oluşturulmuştur. Aylık üretim gücü benzetim programı tarafından hesaplanan FVÜS'nin bulunduğu konumun 1şıma değerleri kullanılarak gün içi saatlerdeki ortalama üretim değerleri hesaplanmıştır. Ayrıca, FVÜS'nin elektrik projelendirmesi yapılarak bağlantı şeması çizilmiştir. Daha sonra otoparkın yük bilgisi alınarak FVÜS'nin ürettiği enerji ile otoparkın ortalama günlük yük eğrisinin karşılaştırılması yapılmıştır. Otoparka kurulan FVÜS'nin gücü $534 \mathrm{kWp}$ olarak hesaplanmıştır. FVÜS toplamda $2770 \mathrm{~m}^{2}$ alanı kaplamaktadır. FVÜS'nde 1617 adet $330 \mathrm{Wp}$ gücünde LG330N1C-A5 marka monokristal güneş paneli kullanılmıştır. Paneller 21 seri modül ve 77 paralel diziden oluşmaktadır. Daha sonra otoparkın bir aylık saatlik tüketim bilgisi kullanılarak otoparkın ortalama günlük yük eğrisi elde edilmiştir. Bu iki bilgi karşılaştırılarak havalimanının enerji analizi yapılmıştır. Bu çalışmanın sonucunda adı geçen havalimanı otoparkına FVÜS'nin kurulumu projelendirmesi hazırlanmıştır. Bu çalışmada teorik ile uygulamanın birleştirilmesi de hedeflenmiştir. Ülkemiz güneş enerjisi bakımından dünyada çoğu ülkeden daha iyi durumdadır. Bundan dolayı güneş enerjisinden elektrik üretimini artırmak enerjide dışa bağımlılığı azaltacaktır. Bu çalışmanın sonuçları da bu konuda yapılacak uygulamalara ışık tutacaktır.

Anahtar Kelimeler: Dağıtık üretim, Fotovoltaik üretim sistemi, Güneş enerjisi santrali, Otopark, Yenilenebilir enerji kaynağı.

\section{Desinging and Energy Analysis of PV System Installed in an Airport Parking Lot}

\begin{abstract}
As the awareness of carbon emission reduction increases around the world, investments from renewable energy sources (RESs) are parallel to this. Especially in our country, photovoltaic (PV) systems are one of the popular subjects of power systems. However, high land prices in metropolitan cities is the biggest obstacle in front of these investments. The PV system to be constructed in the parking
\end{abstract}

\footnotetext{
* Sorumlu Yazar: İstanbul Arel Üniversitesi, Mühendislik-Mimarlık Fakültesi, Elektrik-Elektronik Mühendisliği Bölümü, İstanbul, Türkiye, ORCID: 0000-0003-1085-0474,sguner@arel.edu.tr
} 
lots of public areas such as airports allows both the secondary use of the area of the parking lot and make it more suitable for investors with reducing its investment cost. In addition, the shading area for vehicles can be created to reduce the impact of the sun with the FVUS to be installed in the parking lot. In this study, it is aimed to design a PV system that can be installed in the parking lot of Adnan Menderes Airport and to analyze whether the parking lot meets the energy needs with this PV system. To do this, the PV system is created using a simulation software. Average hourly generation of the PV system is calculated by using hourly irradiation values of the location of the airport and the monthly generation of the PV system which is calculated by the simulation software. In addition, the electrical infrastructure and the connection scheme of the PV system is calculated and drawn. The rated power of the PV system installed in the parking lot is calculated as $534 \mathrm{kWp}$. The PV system covers $2770 \mathrm{~m} 2$ area. In The PV system, 1617 pieces of $330 \mathrm{Wp} \mathrm{LG330N1C-}$ A5 brand monocrystalline solar panels are used. The panels consist of 21 serial modules and 77 parallel arrays. Then, the average daily load curve of the parking lot is obtained using one-month hourly consumption information of the parking lot. The energy analysis of the airport is made by comparing these two information. As a result of this work, the project of the installation of PV system is prepared for this airport parking lot. One of the goals of this study is to combine theory and practice. Our country is better than most countries in terms of solar energy. Therefore, increasing electricity generation from solar energy will reduce dependence on foreign energy resources. The results of this study will shed light on the applications to be made in this regard.

Keywords: Distributed generation, Parking lot, Photovoltaic system, Renewable energy system, Solar energy.

\section{Giriş}

\subsection{Motivasyon}

Kişi başına düşen enerji tüketimi son 10 yıllık dönemde ülkelerin gelişmişlik düzeyini belirleyen parametrelerden biri olarak kabul edilmektedir. Gelişmekte olan ülkeler üretimlerini artırırken buna paralel enerji kaynaklarına olan ihtiyaçları da artmaktadır. Son yıllarda karbon emisyonu azaltımı konusunda oluşan farkındalık ve yenilenebilir enerji kaynaklarından (YEK) elektrik üretiminin maliyetinin düşmesi ve artan enerji ihtiyacı YEK'lere olan ilgiyi artırmıştır. Özellikle fotovoltaik panellerinin fiyatlarındaki dramatik düşüş YEK yatırımlarının artmasında katalizör etkisi yapmıştır. Ayrıca akıllı şebeke ortamının dağıtık enerji sistemlerinin sisteme bağlanmasını kolaylaştırması YEK'lerden elektrik üretimine yardımcı olmaktadır.

Özellikle ülkemizin güney ve güney doğu bölgelerinde arazi fiyatlarının düşük olması fotovoltaik üretim sistemleri (FVÜS) kurulumlarının artmasını sağlamıştır. Fakat büyükşehirlerde arazi fiyatlarının yüksekliği, bu şehirlerde güneş enerjisinden yararlanılmasını engellenmektedir. Bu noktada kamu alanlarının uygun bölümlerine FVÜS'leri kurmak hem bir sistemlerin kurulum maliyetini düşürecek hem de YEK'lerin güç sistemlerine katılımını artıracaktır. Havalimanlarındaki araç sirkülasyonunun fazla olması büyük otopark ihtiyacını ortaya çıkartmaktadır. Büyükşehirlerdeki havalimanlarına kurulacak FVÜS'leri güneş enerjisinden elektrik enerjisi üretimini sağlarken aynı zamanda otoparktaki araçlar için gölgelenme alanı oluşturur. Bunlara ek olarak havalimanının ihtiyaç duyduğu enerjinin belli bölümü üretilebilir.

Ülkemizde yeni nesil YEK'lerden elektrik enerjisi üretimi \%10'un altındadır ve bu üretimin büyük bir kısmını rüzgâr enerjisi sistemleri oluşturmaktadır. Ülkemizin kendi elektrikli aracını üretme sürecinde olduğu bu dönemde bu araçların hem karbon emisyonunun azaltılmasına yardımcı olması hem de bu araçların ihtiyaç duyduğu enerjinin yerli kaynaktan karşılanması hedeflerinin gerçekleşmesi için güneş enerjisinden elektrik enerjisi üretiminin artırılması elzemdir. Bundan dolayı YEK'lerden elektrik enerjisi üretilebilecek her alanın fizibilitesi yapılarak kullanılması güneş enerjisinin güç sistemine katılımını artıracaktır. Havaalanlarının büyük otoparklarının alanları bu amaca hizmet edecek yerlerden biridir.

Ülkemizin yılda ortalama 2741 saat güneş ışınlarından yararlanmaktadır. Ülkemizde 2019 yılı sonunda güneş enerjisi santrallerinin kurulu gücü $5.9952 \mathrm{GW}$ ’a ulaşmıştır (TC Enerji ve Tabii Kaynaklar Bakanlı̆̆ı, 2019). Bu üretim miktarı toplam kurulu gücü $91 \mathrm{GW}$ olan ülkemiz için çok düşüktür. Ülkemizin güneşlenme süresini daha verimli olarak FVÜS'leri ile elektrik enerjisine dönüştürmek ülkemizin enerjide dışa bağımlılı̆̆ını da azaltacaktır. Bundan dolayı ülkemizin güneş enerjisi potansiyelini kullanmak için yatırım maliyeti daha düşük olan kamusal alanlardan yararlanmak iyi bir ç̧̈züm olarak durmaktadır. Bu çalışmada ülkemizdeki bir büyükşehirde bulunan havalimanının otoparkına kurulacak FVÜS'nin benzetim çalışması yapılarak otoparkın enerji ihtiyacının karşılanması amaçlanmıştır. Bu çalışma kamu alanlarından ikincil fayda sağlamanın olumlu etkisini ortaya koymaktadır. Bu çalışmanın sonuçları farklı kamusal alanlardan da FVÜS'leri için yararlanılmasına yardımcı olacaktır. Bu çalışmanın temel amacı, Adnan Menderes Havalimanı otoparkına kurulabilecek $534 \mathrm{kWp}$ gücünde FVÜS'nin tasarımını ve otoparkın günlük yük ihtiyacına göre enerji analizini yapmaktır.

\subsection{Literatür Özeti}

Küresel ısınmanın etkileri sonucunda oluşan iklim düzensizliklerinden dolayı birçok ülke karbon emisyonunun azaltılması için eylem planları geliştirmiştir. Avrupa Birliği 2030'a kadar karbon emisyonunu 1990'daki seviyelerinden en az \%40 azaltmayı ve üretilen enerjinin en az \%32'sinin YEK'lerden üretmeyi planlamaktadır (European Commission, 2020). Bizim gibi petrol fakiri ülkelerin dişa bağımlılı̆̆ını azaltacak tek yol YEK'lerden üretilen enerjiyi artırmaktır. Fakat YEK'lerden elektrik enerjisi üretmenin en önemli olumsuzluğu kaynakların sürekli olmayan yapısıdır ve bu durum bu üreteçler güç sistemlerinin yönetimini zorlaştırmaktadır. Fakat bu üreteçler dağıtık enerji kaynağı olarak tüketime yakın konumlandırılırsa yönetimi daha kolay olur. Bundan dolayı bir havalimanı otoparkına kurulacak bir FVÜS hem YEK'den yararlanmayı hem de üretilen enerjinin daha kolay yönetilmesini sağlamaktadır. Günümüzde maliyeti yüksek santraller kurmaktan uzak durmaktadır. Bu yüzden YEK kullanan dağıtık üretim sistemlerinin arazi maliyeti olmayan kamu alanlarına kurulması hem ekonomik hem de temiz bir çözüm olarak tercih edilebilir. 
Otoparklara FVÜS kurulması yeni bir olgu değildir. Birçok ülkede örnekleri bulunmaktadır (Ingersoll ve Perkins, 1996; Solar Power World, 2019; Maryland Energy Administration, 2019; Root ve Perez, 2019). Bu çalışmalar üzeri açık otoparklarda uygulanmaktadır ve bu şekilde araçların gölgelenmesi de sağlanmaktadır. Bunlara ek olarak (Figueiredo, vd. 2017)'de yapılan çalışmada bir otoparkın çatısına kurulan FVÜS'nin ortalama 7 yılda yatırım maliyetini amorti ettiği gösterilmiştir.

Literatürdeki otoparkların ve FVÜS'lerinin elektrik şebekesine göre en uygun konum veya boyut belirlenmesi ile ilgili yapılan çalışmalar yeni kurulacak otoparklara yol gösterici olacağı şüphe götürmez bir gerçektir (Fazelpour, vd., 2014; Neyestani, vd., 2015; Rahmani-Andebili ve Venayagamoorthy, 2015; Lee ve Park, 2015). Fakat mevcut otoparkların elektrikli araç kullanıcılarının memnuniyeti artırmak, FVÜS ile bütünleştirmek ve elektrik şebekesinin kalitesini geliştirmek için katkılarını artırmak, yeni bir otoparkın sistem yararına tasarlanması kadar önemlidir.

Akıllı otopark yönetim sistemleri ile YEK'lerin birleştirildiği sanal mikro şebeke çalışmaları da literatürde mevcuttur (Hoarau ve Perez, 2018; Alghoul, vd., 2018; Lee, vd., 2016). Bu çalışmalar test sistemleri kullanılmaktadır. Test sistemlerle oluşturulan çalışmalar bilim açısından önemli olsa da gerçek dünyayı gerçek sistem verileri kullanarak benzetmek daha gerçekçi sonuçlara ulaşılmasını sağlayacaktır.

(Tulpule, vd., 2013)'te, işyerlerinde bulunan otoparklar için FVÜS'nin kurulumunun uygunluğu ile ilgili araştırmalar yapılmıştır. Bunun için, iki farklı bölgenin (Columbus ve Los Angeles) yıllık güneş ışınımı ve finans yapısı farklı senaryolar uygulayarak sonuçları ortaya konmaktadır.. Ayrıca, (Sedighizadeh, vd., 2109)'de, FVÜS'ne sahip otoparklara en uygun enerji yönetim sistemini tasarlamak için, Multi-Layer Perceptron Artificial Neural Network (MLP-ANN) yaklaşımını dikkate alan Approximate Dynamic Programing (ADP) ve Hybrid Big Bang Big Crunch (HBB-BC) algoritmasına dayanan iki aşamalı bir optimizasyon sistemi üzerine çalışılmıştır.

Literatürde bu çalışmanın kapsamında olmayan çalışmalar da vardır (Tushar, vd., 2016; Coffman, vd., 2017). 20 yıllık projeksiyonda otoparklara FVÜS kurulmasının faydalarından biri de otoparka gelecek elektrikli araçların şarj ihtiyaçlarını yeşil bir güç kaynağından sağlanmasıdır. Otoparklar, elektrikli araçların gün içi saatlerde şarj koordinasyonunu ve YEK'ler ile entegrasyonunu kolaylaştıran bir toplayıcıdır. Otoparklar dışında merkezi toplayıcıların tanımladığı ve elektrikli araçların şarj yükünün YEK'lerden (özellikle FVÜS'nden) karşılandığı çalışmalar da vardır (Zakariazadeh, vd., 2015; Hoarau ve Perez, 2018). Ayrıca, (Nunes, vd., 2016)'de FVÜS'ne sahip elektrikli araç otoparklarının teknik, çevre ve finansal konularda literatür taraması sunulmuştur.

\section{3. Çalışmanın Katkıları}

Bu çalışmada gerçek bir havalimanı otoparkına kurulabilecek FVÜS'nin tasarımı her aşaması ile yapılmıştır. Bu çalışmanın sonucunda hem üretim bilgileri hem de bağlantı şemaları kullanılarak ismi belirtilen havalimanına FVÜS kurulum imkânı vermektedir. Bu çalışmanın sonuçları kamu alanlarından maksimum fayda elde etmek için kurulabilecek YEK'lerden elektrik enerjisi üreten diğer üretim sistemlerinin kurulumlarına da yol gösterici olacaktır.

Bu çalışma, aşağıdaki ana aşamalardan oluşmaktadır:

- Belirlenen otoparka kurulacak FVÜS üretim bilgilerinin hesaplanması için bir benzetim yazılımı kullanılarak otoparkın coğrafik konumu bilgisi ile beraber tasarımı yapılmıştır. Bu şekilde FVÜS'nin yılın her ayı için toplam üretim bilgisine ulaşılır.

- Otoparkın yoğun olduğu aylardan biri olan Temmuz ayına ait yük bilgileri alınarak otoparkın günlük ortalama yük eğrisi oluş̧urulmuştur.

- Oluşturulan iki modelin bilgileri kullanılarak otoparkın elektrik enerjisi ihtiyacının FVÜS ile nasıl karşılanacağının analizi yapilmıştır.

Bu çalışmada FVÜS üretim, sistem bilgileri ve otoparkın günlük yük eğrisinin hesaplanması ile ilgili süreçler 2. bölümde, benzetim ve enerji analizi sonuçları ise 3 . bölümde anlatılmıştır. Çalışmanın sonuç kısmı 4. bölümde sunulmuştur.

\section{Materyal ve Metot}

\subsection{FVÜS Tanıtımı ve Kurulumu}

Bu çalı̧̧mada daha önce de belirtildiği gibi Adnan Menderes Havalimanı Otoparkına bir FVÜS benzetim yazılımı ile tasarlanmıştır. Bu sistemin konumu olarak $38^{\circ} 29^{\prime}$ kuzey enlemi ile $27^{\circ} 15^{\prime}$ ' doğu boylamı belirlenmiştir. FVÜS'nin panellerinin eğimi $10^{\circ}$ belirlenmiş, azimut açısı $13^{\circ}$ olarak hesaplanmıştır. FVÜS'nin $2770 \mathrm{~m}^{2}$ alana kurulması planlanmaktadır. Ayrıca, belirtilen alanda 1617 adet $330 \mathrm{Wp}$ gücünde monokristal fotovoltaik panel bulunmaktadır. Bu paneller 21 seri ve 77 paralel dizi şekilde yerleştirilmiştir.

FVÜS toplamda $2770 \mathrm{~m}^{2}$ alanı kaplamaktadır. FVÜS'nde 1617 adet $330 \mathrm{Wp}$ gücünde LG330N1C-A5 marka monokristal güneş paneli kullanılmıştır. Paneller 21 seri modül ve 77 paralel diziden oluşmaktadır. Buna ek olarak, FVÜS'nin otopark şebekesine bağlanabilmesi için 7 adet $66 \mathrm{~kW}$ gücünde 3 fazlı şebekeye bağlı merkezi invertör bulunmaktadır. Bu çalışmada tasarlanan FVÜS'nin yerleşimi Şekil 1'de, FVÜS'nin yapılması planlanan konumunun iso gölgelendirmesi Şekil 2'de verilmiştir. 
Şekil 1. FVÜS'nin Yerleşimi

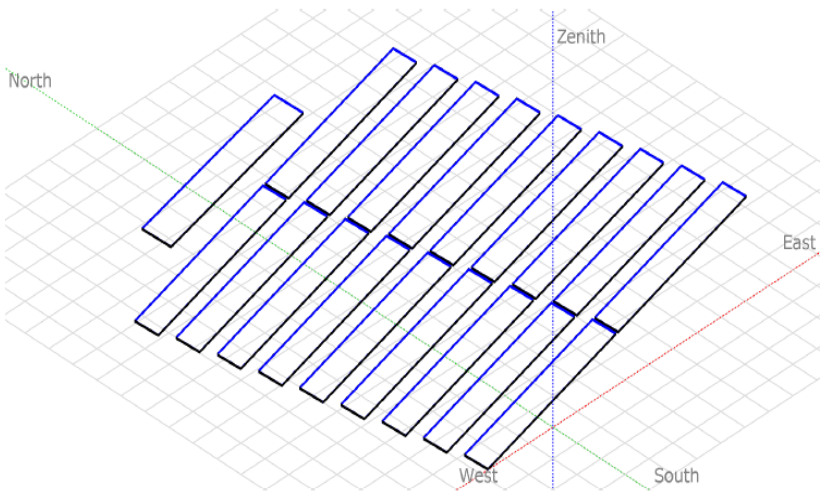

Şekil 2. FVÜS'nin bulunduğu konumun iso gölgelendirmesi

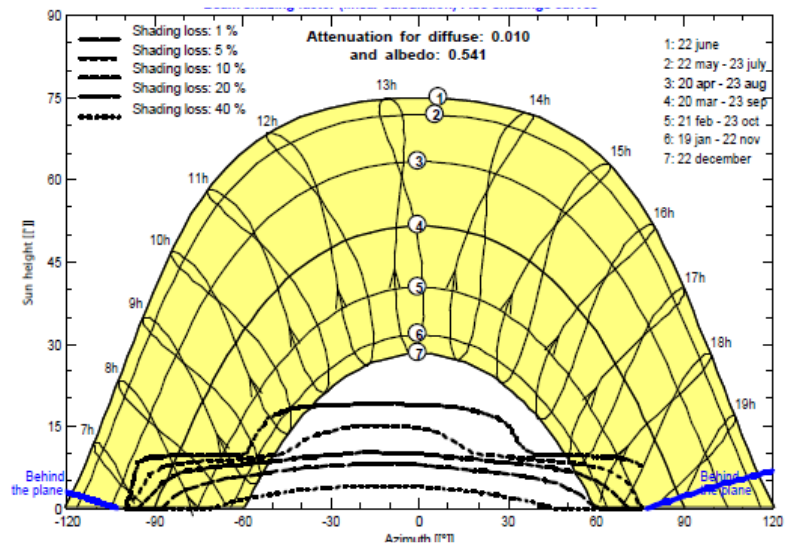

Bu FVÜS carport tipinde tasarlanmıştır. Carport tipi tasarım araçların doğa koşullarından olabildiğince az etkilenmesi için seçilmiştir. Bu FVÜS İzmir gibi güneş 1şınlarının kuvvetli olduğu bir bölge olduğundan dolayı özellikle yaz aylarında sürücülerin konforunu artırması beklenmektedir. Aynı şekilde kış aylarının sert geçtiği illerde bu sistem uygulandığında kar ve dolu gibi hava olaylarından araçların korunması sağlanabilir. Bu çalışmada kullanılan tasarıma uygun dayanıma sahip çelik taşıyıcı sistem Şekil 3'de verilmiştir. Carport taşıyıcı sistem iki taraflı olarak biçimlendirilmiştir. Her carporta 2 fotovoltaik panel olmak üzere 21 seri sistem için toplam 42 adet panel yerleşimi Şekil 4'de verilmiştir. Carport taşıyıcı sistem güneydoğu yönünde $140^{\circ}$ açıyla yerleştirilmiştir. Havalimanın otoparkının tamamını carport tipi taşıyıcılı panellerle kapatılmıştır ve carportun çatı eğimi $6^{\circ}$ olarak belirlenmiştir. Carportun alçak tarafının yerden yüksekliği $2.9 \mathrm{~m}$, yüksek tarafı $4 \mathrm{~m}$ olarak ayarlanmıştır. $534 \mathrm{kWp}$ güce sahip FVÜS'nin taşıyıcı sistemi modüler olarak hazırlanmıştır. FVÜS'nde bulunan toplam 1617 adet panelin toplam ağırlığı 270 ton olarak hesaplanmıştır.

Şekil 3. Carport Tipi Fotovoltaik Panel Çelik Taşıyıcı Sistemi

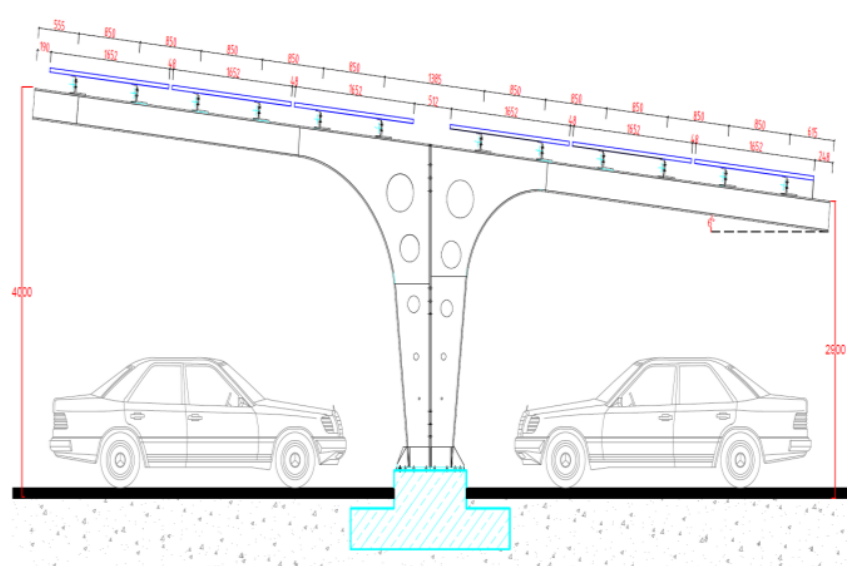

Şekil 4. Carport Fotovoltaik Panel Yerleşimi

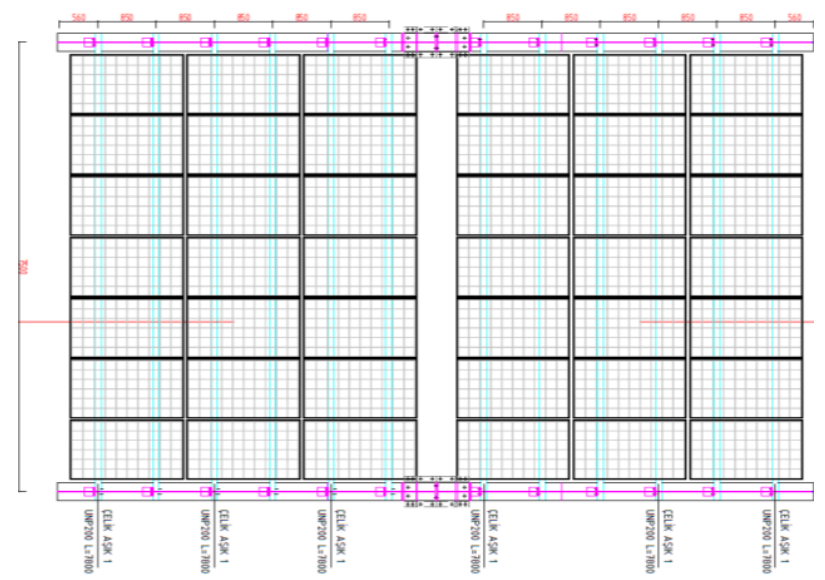

\subsection{FVÜS'nin Elektrik Tesisat Projesi}

Bu çalışmada bahsi geçen havalimanının otoparkı 2523 araç kapasitesine sahiptir. FVÜS'ndeki panellerin bağlantı şeması Şekil 5'de verilmiştir. Bu şemada 21 seri panel dizisi birbirine seri olarak bağlanmıştır. Panel dizisinde $6 \mathrm{~mm}^{2}$ PV1-F solar kablo kullanılmıştır. FVÜS'nin bağlandığı 2 adet tali dağıtım panosu bulunmaktadır ve bunlar TD1 ve TD2 olarak adlandırılmıştır. İnvertörler ile tali dağıtım panoları arasında $4 * 70 \mathrm{~mm}^{2} \mathrm{NYY}$ tipi kablo kullanılmıştır. Ayrıca TD1 panosu ile ana pano arasındaki bağlantı için 2 set $4 * 1 * 150 \mathrm{~mm}^{2}$, TD1 panosu ile ana pano arasındaki bağlantı için 2 set $4 * 1 * 95 \mathrm{~mm}^{2}$ NYY tipi kablo kullanılmıştır. Kablo çaplarındaki farkı TD1 panosunun kurulu gücünün $264 \mathrm{~kW}$, TD2 panosunun kurulu gücünün $198 \mathrm{~kW}$ olması yaratmıştır.

Şekil 5. FV Panel Băglantı Şeması 


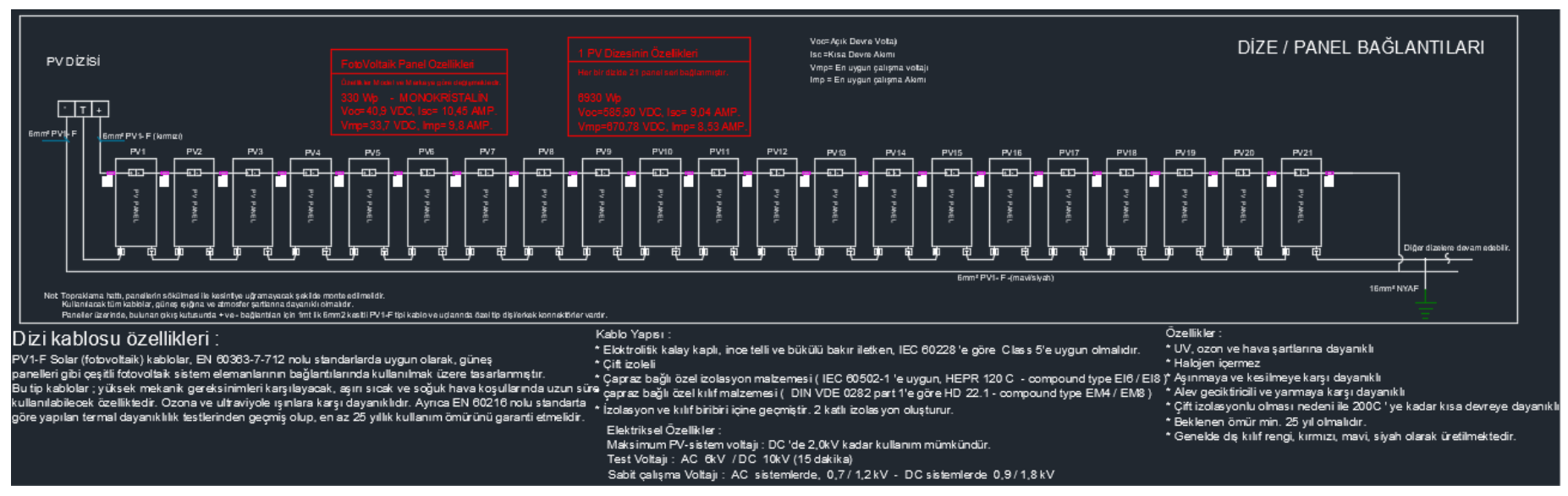

Şekil 3.11. Fotovoltaik Panel Detayları

\subsection{FVÜS Üretim Bilgisi}

Bu çalışmada tasarlanan FVÜS’nin teknik bilgileri bir önceki bölümde verilmiştir. Bu sistemin üretim bilgisi bir benzetim yazılımı kullanılarak hesaplanmıştır. Bu hesaplamanın sonucunda FVÜS'nin yıllık üretim tahmini her ay için Şekil 6'de verildiği gibi bulunmuştur. Verilen grafikte de görüldüğü gibi güneşlenme süresinin en yüksek seviyeye çıktığı Temmuz ayında toplam üretim tahmini 106 MWh olarak verilmektedir. Ayrıca, kış aylarında güneşlenme süresine bağlı olarak Aralık ayında üretimin 34.4 MWh'e kadar düşmektedir. Bu FVÜS’nin yıllık toplam üretimin 862.5 MWh olarak hesaplanmıştır.

Şekil 6. FVÜS’nin Yıllık Üretim Tahmini

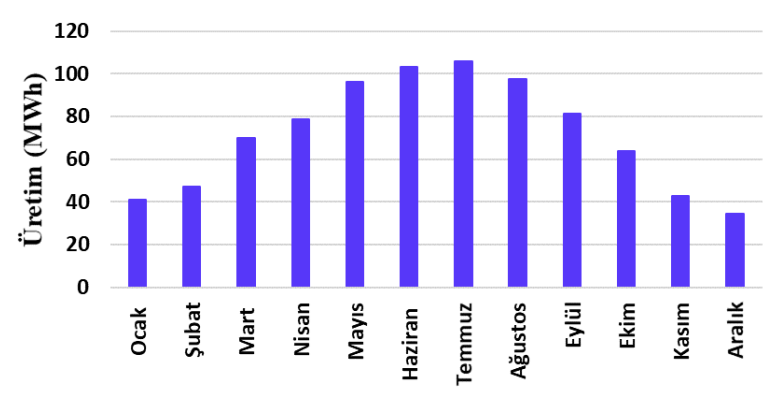

Bu çalışma bir havalimanı otoparkı için planlandığından dolayı hem otoparkın araç yoğunluğu hem de FVÜS 'nin üretim seviyesi dikkate alınarak Temmuz ayının üretim değerlerine odaklanılmasına karar verilmiştir. Otoparkın günlük yük ihtiyacının FVÜS saatlik üretiminin karşılaştırılması için FVÜS saatlik üretim değerlerine ihtiyaç duyulmaktadır. Bu çalışmada kullanılan yazılımdan bu bilgiye ulaşılamadığından dolayı Avrupa Birliği tarafından sağlanan fotovoltaik coğrafi bilgi sistemi üzerinden FVÜS 'nin konumunun Temmuz ayı için saatlik ortalama güneşlenme 1şınımı bilgisi elde edilmiştir (European Commission, 2020). Şekil 7'de FVÜS'nin konumun güneşlenme 1şınımı verilmiştir. Şekil 6 ve 7'da verilen bilgiler kullanılarak yapılan hesaplamada FVÜS'nin Temmuz için günlük üretim bilgisi Şekil 8'de verilmiştir. Bu şekilde de görüldüğü gibi gün ortasında FVÜS 416 kW gücünde elektrik enerjisi üretebilmektedir.

Şekil 7. FVÜS'nin Konumunu Temmuz için Güneşlenme Işınımı

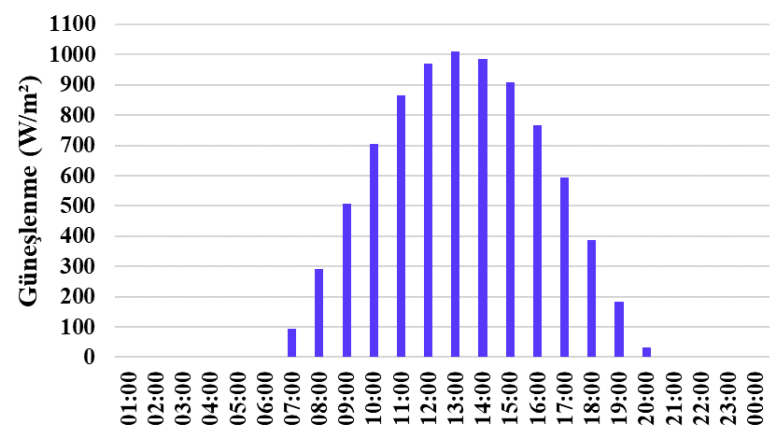

Şekil 8. FVÜS'nin Temmuz için Hesaplanan Günlük Enerji Üretimi

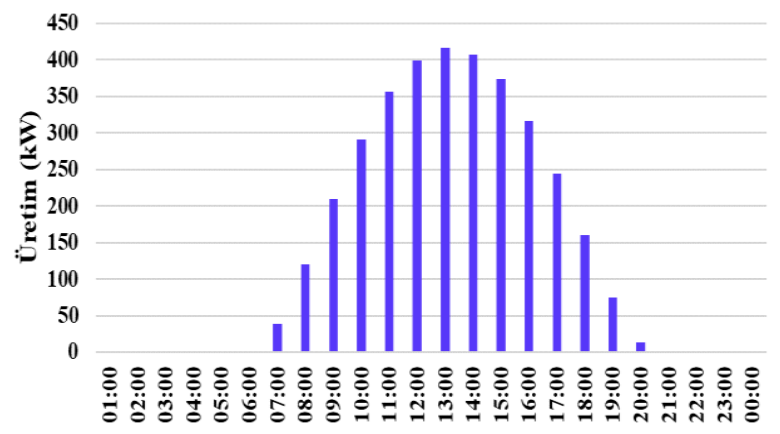

\subsection{Otoparkın Günlük Yük Eğrisi}

Adnan Menderes Havalimanı'nın otoparkı iç hatlar ve dış hatlar olmak üzere iki bölgeden oluşmaktadır. Bu iki bölgenin ayrı ayrı Temmuz 2018 ayına ait saatlik tüketim bilgisi elde edilmiştir. Bu bilgi işlenerek iki bölgenin günlük ortalama yük eğrisini belirlenmiştir. Havalimanının iç hatlar otoparkına ait günlük yük eğrisi Şekil 9'da, dış hatlar otoparkına ait günlük yük eğrisi Şekil 10'da verilmiştir. 
Tahmin edileceği gibi otoparkın günlük enerji tüketimi aydınlatma ağırlıklı olduğunda dolayı gece saatlerinde tepe noktaya ulaşmaktadır. İç hatlar otoparkında tüketim ortalama maksimum $184 \mathrm{~kW}$ güce ulaşılırken, Dış hatlarda ise ortalama maksimum tüketim $118 \mathrm{~kW}$ güce ulaşılmaktadır. Bu bilgiler FVÜS’nin üretim bilgileri ile karşılaştırılarak enerji analizi 3. bölümde yapılacaktır.

Şekil 9. Havalimanı İ̧ Hatlar Otoparkının Günlük Yük Eğrisi

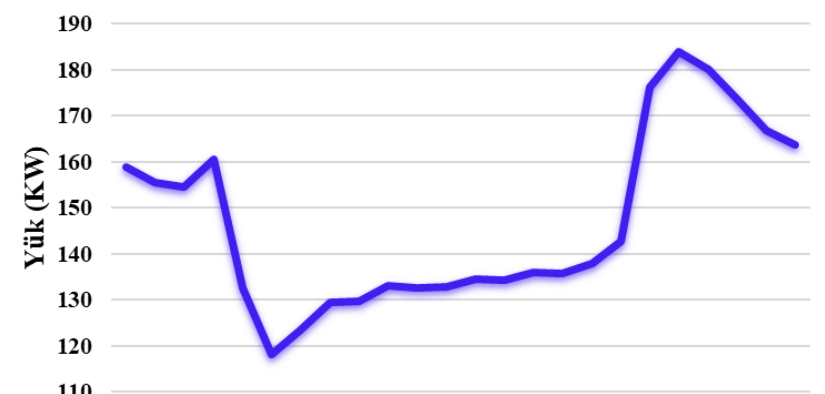

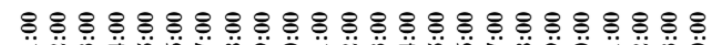

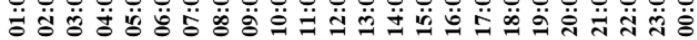

Şekil 10. Havalimanı Dış Hatlar Otoparkının Günlük Yük Ë̆risi

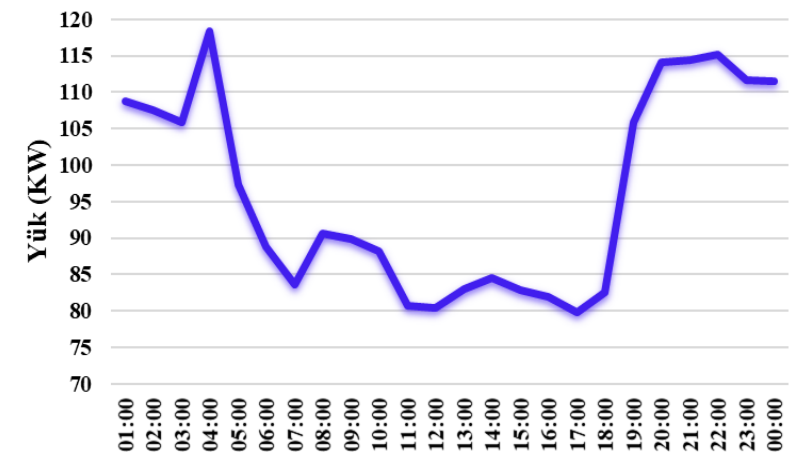

\section{Araştırma Sonuçları}

FVÜS'nin üretim hesaplamaları ve bağlantı șeması bir önceki bölümde ayrıntılı olarak anlatılmıștır. Ayrıca, hem iç hatlar hem de dış hatlar otoparklarının günlük yük eğrisi bulunarak bu bilgiler üretim-tüketim karşslaş̧ırılması yapılmış̧ır. Bu üretim-tüketim karşılaştırma grafiği Şekil 11'de verilmiştir. Bu grafikte görüldüğü gibi FVÜS her iki otoparkın gün içi saatlerdeki ihtiyacından daha fazla enerji üretmektedir. Bu üretim yaklaşı $200 \mathrm{~kW}$ fazla güç üretmektedir. Diğer taraftan FVÜS'nin enerji üretmediği ve otoparkın enerji ihtiyacının fazla olduğu akşam saatleri için otoparkın gün için saatlerde ürettiği fazla enerjinin depolanarak kullanılması düşünülebilir.

Şekil 11. FVÜS ile Havalimanı Otoparklarının Üretim-Tüketim Karşılaştırması

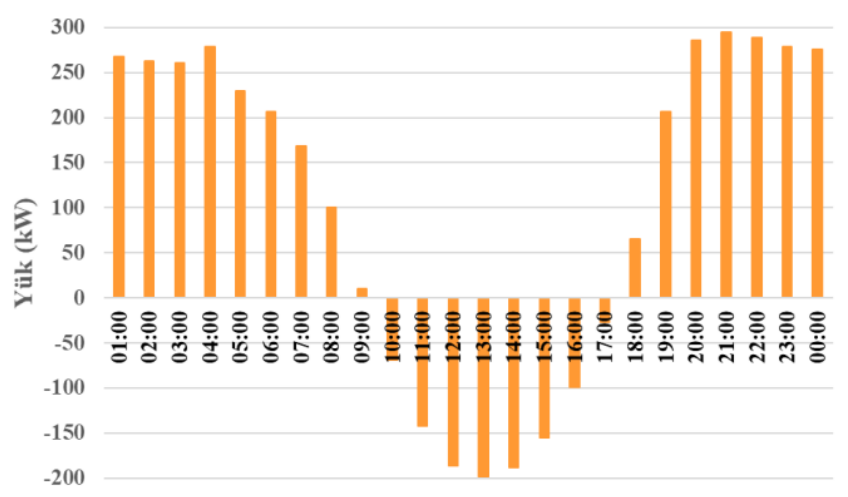

$\mathrm{Bu}$ çalışmanın hedeflerinden biri kamu alanlarının ikincil kullanımı ile YEK'lerden daha fazla faydalanmaktır. Ayrıca bu çalışmanın sonuçları yakın bir gelecekte kullanım sıklığı artacak elektrikli araçların YEK'den şarj edilmesine de imkân sağlayacaktır. Havalimanı gibi araçların park süreliğinin uzunluğu düşünüldüğünde elektrikli araçların sayısı artıkça gün içi saatlerdeki FVÜS tarafından üretilen fazla enerjinin de kullanılması ve/veya depolanması düşünülebilir. Ayrıca optimum enerji yönetimi algoritmaları kullanılarak FVÜS'nin ürettiği enerji ile hem otopark yükü hem de elektrikli araç şarj ihtiyacını daha verimli karşılanabilir.

\section{Sonuç}

Gelişen ve değişen dünyada ülkeler büyük maliyetli santraller kurmaktansa küçük ölçekli tüketiciye yakın dağıtık üretim sistemleri daha olumlu bakmaktadırlar. Ayrıca küresel iklim değişikliğinin etkilerinin azaltılması için bu dağıtık üretim sistemlerinde YEK'lerin kullanılması önemlidir. Bu çalışmada havalimanı otoparkı gibi kamu alanına kurulabilecek carport tipi FVÜS'nin kazanımları ortaya konulmuştur. Çalışmada gerçek bir havalimanına odaklanılarak çalışmanın gerçekliği ortaya konulmuştur. Ayrıca bu FVÜS'nin üretim tahminleriyle beraber elektrik tesisat projesi de çizilerek uygulanmaya hazır bir proje haline dönüştürülmüştür. Çalışmanın son bölümünde havalimanının otoparklarının günlük yük bilgileri ile FVÜS'nin üretim bilgisi karşılaştırılarak havalimanı otoparkının enerji analizi yapılmıştır.

YEK'lerden elektrik enerjisi üretilirken bu kaynakların kesikli yapısı göz ardı edilemez. Bundan dolayı FVÜS'lerinin belli bir depolama birimi bir ile çalışması kaynağın enerji kalitesini ve güvenilirliğini artıracaktır. Depolama birimi ihtiyacı yakın gelecekte sıklıkla kullanılacak elektrikli araçların bataryalarıyla da giderilebilir. Akıllı şebekelerin temel amaçlarından biri daha fazla yeşil kaynaktan küçük ölçekli üreteçlerin sayısının artırılmasıdır. Bu amaca hizmet edecek FVÜS'lerinin sayısının artırılmak için her türlü imkândan yararlanılması kuşkusuz çok önemlidir. Bu noktada havalimanı gibi arazi maliyetinin olmadığı kamu alanlarından yararlanılması yerli enerji kaynaklarının elektrik güç sistemine katılımını artıracaktır. 


\section{Teşekkür}

Bu çalışma 119E646 Hibe projesi kapsamında Türkiye Bilimsel ve Teknolojik Araştırma Kurumu (TÜBİTAK) tarafından desteklenmiştir.

\section{Kaynakça}

Alghoul, M. A., Hammadi, F. Y., Amin, N., Asim, N., 2018. "The role of existing infrastructure of fuel stations in deploying solar charging systems, electric vehicles and solar energy: A preliminary analysis", Technological Forecasting \& Social Change, 137, $317-326$.

Coffman, M., Bernstein, P., Wee, S., 2017. "Integrating electric vehicles and residential solar PV", Transport Policy, 53, 30 - 38.

European Commission, https://ec.europa.eu/clima/policies/strategies/2030_en. Son erişim tarihi: 13 Mart 2020

European Commission, Photovoltaic Geographical Information System,

https://re.jrc.ec.europa.eu/pvg_tools/en/tools.html. Son erişim tarihi: 13 Mart 2020.

Fazelpour, F., Vafaeipour, M., Rahbari, O., Rosen, M. A., 2014. "Intelligent optimization to integrate a plug-in hybrid electric vehicle smart parking lot with renewable energy resources and enhance grid characteristics", Energy Conversion and Management, 77, 250 -261 .

Figueiredo, R., Nunes, P., Brito, M. C., 2017. "The feasibility of solar parking lots for electric vehicles", Energy, 140, 1182 - 1197.

Hoarau, Q., Perez, Y., 2018, "Interactions between electric mobility and photovoltaic generation: A review", Renewable and Sustainable Energy Reviews, 94, $510-522$.

Ingersol, J. G, Perkins, C. A. 1996. " The $2.1 \mathrm{~kW}$ photovoltaic electric vehicle charging station in the city of Santa Monica, California", Conference Record of The 25th IEEE Photovoltaic Specialists Conference, Washington, DC, USA.

Lee, J., Park, G. L., 2015. "Dual battery management for renewable energy integration in EV charging stations", Neurocomputing, 148, $181-186$.

Lee, S., Iyengar, S., Irwin, D., Shenoy, P., 2016. "Shared solar-powered EV charging stations: feasibility and benefits", $20167^{\text {th }}$ International Green and Sustainable Computing Conference (IGSC), Hangzhou, China.

Maryland Energy Administration. "Parking lot solar PV canopy with EV charger grant program" https://energy.maryland.gov/business/Pages/incentives/PVEVprogram.aspx. Son erişim tarihi: 13 Şubat 2020

Neyestani, N., Damavandi, M.Y., Shafie-Khah, M., Contreras, J., Catalão, J. P. S., 2015. "Allocation of plug-in vehicles' parking lots in distribution systems considering network-constrained objectives", IEEE Transaction on Power Systems, 30(5), 2643 - 2656.

Nunes, P., Figueiredo, R., Brito, M. C., 2016. "The use of parking lots to solar-charge electric vehicles", Renewable and Sustainable Energy Reviews, 66, 679-693.

Rahmani-Andebili, M., Venayagamoorthy, G.K. 2015. "SmartPark placement and operation for improving system reliability and market participation", Electric Power System. Research, 123, 21 - 30.

Root L, Perez R., "Photovoltaic covered parking lots - a survey of deployable space in the Hudson River Valley, New York city, and Long Island, New York" http://asrc.albany.edu/people/faculty/perez/publications/Other\%20Papers\%20and\%20Applications/parkings.pdf. Son erişim tarihi: 13 Şubat 2020

Sedighizadeh, M., Mohammadpour, A., Alavi, S. M. M., "A daytime optimal stochastic energy management for EV commercial parking lots by using approximate dynamic programming and hybrid big bang big crunch algorithm", Sustainable Cities and Society, 45, $486-498$.

Solar Power World. "Photoblog: Assurant celebrates earth day with new solar array" https://www.solarpowerworldonline.com/2013/04/photoblog-assurant-celebrates-earth-day-with-new-solar-array/ Son erişim tarihi: 13 Şubat 2020

TC Enerji ve Tabii Kaynaklar Bakanlığı, 2019, http://www.enerji.gov.tr. Son erişim tarihi: 13 Mart 2020.

Tulpule, P. J., Marano, V., Yurkovich, S., Rizzoni, G., 2013. "Economic and environmental impacts of a PV powered workplace parking garage charging station", Applied Energy, 108, 323 - 332.

Tushar, W., Yuen, C., Huang, S., Smith, D. B., Poor, H. V., 2016, "Cost minimization of charging stations with photovoltaics: an approach with EV classification", IEEE Transaction on Intelligent Transportation Systems, 17(1), 156 - 169.

Zakariazadeh, A., Jadid, S., Siano, P., 2015. "Integrated operation of electric vehicles and renewable generation in a smart distribution system", Energy Conversion and Management, 89, $99-110$. 